Proc. of the Sixth International Conference on Advances in Social Science, Management and Human Behaviour - SMHB 2017. Copyright (C) Institute of Research Engineers and Doctors. All rights reserved.

ISBN: 978-1-63248-141-2 doi: 10.15224/ 978-1-63248-141-2-47

\title{
A retrospective analysis of addressing higher education students' socio-cultural differences in the Ethiopian educational systems and the prospect of multicultural approach
}

By

*Hailemariam Kekeba Gobena (PhD)

\begin{abstract}
The main purpose of this study was to examine trends of treating within-country higher education students' socio-cultural differences in the Ethiopian education systems retrospectively and find evidence based explanation with regard to the level of effectiveness of the current multicultural approach for managing student diversity. The study used qualitative data collected from ranges of policystrategy documents and documented higher education student intergroup scenarios in the country today. The findings showed that during the Imperial regime assimilation was practiced where as during the Dergue era integration strategy was employed to bring about social cohesion in the institutions. These approaches did not bring about the envisaged peace in the country that the present EPRDF government which had seized government power and which had emerged from the student struggle itself installed a multicultural policy. Nevertheless, ethnic, linguistic and religious based mistrust and hostilities have been prevailing at universities since the implementation of the Policy. The findings suggested that ethnic, linguistic and religious diversity variables are equally vital and that the multicultural approach hardly resolved the multifaceted student flashpoints. The study suggested that the treatment of sociocultural diversity in the present educational system seems to be at a crossroad. It was recommended that in order to mitigate the prevailing identity based mistrust and hostility of students, a transformational diversity management approach that goes beyond the 'unity within diversity' in which both differences and commonalities are equally embraced and celebrated should be developed that people would develop the attitude of "I am, because we are".
\end{abstract}

\section{Introduction}

Enrolment of diverse students is inescapable in most of the present universities. Most importantly, the nondisability social diversity issues have become phenomena in the current student population due to societal mobility, access and equity of educational opportunities.

Now, admitting diverse student population has often been considered as a major success of managing

*Assistant professor, College of Education and Behavioral Studies, Addis Ababa University diversity at higher institutions. Gurin (1999) (in Fries-Britt, Younger \& Hall 2010: 183), however,

contend that managing diversity should not be measured solely by the enrolment of diverse students or, even the installation of specific diversity related programs into a curriculum; rather it has to be measured by the appropriateness of the approach applied to address aspects of diversity in the context. Inappropriate management processes installed in an institution may enhance intergroup differences and instill mistrust and suspicion that could become a potential for inter-group conflicts (Cox (1994) in Dancy II 2010: 86). Gupta (2006), (in Onsman 2010: 109-110) complains that "the biggest problem of the $21^{\text {st }}$ century [education] is rapidly expanding diversity, along with stubbornly persistent inequities in terms of status and power based upon caste, race, ethnicity, class, language, citizenship or region".

In most cases, local students of a country are seen as homogeneous and their socio-cultural differences have often been overlooked with the assumption that the differences are less significant and have less impact on their educational success. It is argued that labeling different ethnic groups into a homogeneous crude general category would lead to loss of sight to important uniqueness and differences which could not be less than discrimination (Gillborn 1990: 5). In a country where multicultural students come together for higher education from diverse ethnic, linguistic and religious backgrounds and are ostensibly considered as homogenous, there might be diversity concerns that might transcend the international principles of minority-majority treatment. Where the identity of an individual or a group is not recognized, students may not feel at ease and may console themselves within identity boundaries. Thus, they would hustle with both the social and academic challenges. Particularly, in non-racial multicultural contexts where cultural differences dictate social relationships, ethnic, linguistic and religious variables would determine forms of inter-group interaction in teaching and learning environments.

\section{Statement of the problem}


Proc. of the Sixth International Conference on Advances in Social Science, Management and Human Behaviour - SMHB 2017. Copyright (๑) Institute of Research Engineers and Doctors. All rights reserved.

ISBN: 978-1-63248-141-2 doi: 10.15224/ 978-1-63248-141-2-47

It has been contended that in a multicultural country context governance system applied in a society is often promoted in the schooling system. Shizah and Abdi (2005: 242) argue that "policies and legislation on education are based on the historical, political, and ideological persuasion of the ruling party at any given time". This theoretical assumption holds true to Ethiopian governments where the governance systems prescribed for the society have been dictating the nature of the educational system. Ethiopia is a country of diverse cultures and ethnic groups and is signified as a multicultural country. There are more than eighty six ethnic communities which have recorded both peaceful co-existence and intergroup hostile historical scenarios ever since the early times to the present (Tjeldvoll, Welle-Strand \& Bento 2005: 62; Balsvik 2007: 37-38).

Documentary sources show that different Ethiopian governments employed different policy strategies in order to address socio-cultural differences in their education systems. For instance, the educational policy during Menilik II (1886-1912) and Hailesilassie I (1930-1974) era disregarded sociocultural differences related to ethnic, linguistic, and religious backgrounds. The policy of the Dergue regime (1974-1991) gave recognition to sociocultural differences in the country but followed the pattern of its predecessors in treating the differences. Contrary to these backdrops, the EPRDF government has explicitly set multiculturalism through the Ethiopian Education and Training Policy (1994). The multicultural policy framework has been implemented by means of Civics and Ethical Education and Communicative English Skills courses which have been given across all universities and aim at fostering good citizenship and multiculturalism (FMOE 2005: 25; Saint 2004: 86). The purpose of this study was to retrospectively examine the trends of addressing student socio-cultural differences in the Ethiopian educational systems and explain the prospect of the multicultural approach in the study context.

\section{A. Research questions}

This study attempts to provide explanations for the research following questions:

1. How progressive have the educational policies of different Ethiopian regimes been to address the diversity needs of students?

2. Why do student intergroup mistrust, stereotype and flashpoints persist among students despite the implementation of multicultural policy?

3. How do social and political imperatives underlie the development of policy for treating intergroup relations?

\section{B. Research objectives}

The present study aims to

1. Identify progression level of Ethiopian educational policies of Ethiopian regimes in addressing student diversity needs at higher education.

2. Provide evidence based explanations why student intergroup mistrust, stereotype and flashpoints persist in the Ethiopian higher institutions.

3. Identify social and political imperatives that underlie the development of policy for the treatment of intergroup relations.

\section{The place of a within-country identity factors in educational processes}

\section{A. The role of diversity variables}

Global literatures on diversity studies show that student differences have been addressed through approaches such as intercultural, cross-cultural, pluralism; multicultural, inclusive and special needs and citizenship education approaches (Glazer 1997: 8; Figueroa 1999: 283). However, literatures also emphasize that the theoretical foundations of these approaches are largely rooted within the racial, ethnic, and cultural majority-minority, nativeimmigrant and ability-disability paradigms that they are less comprehensive to adequately address the multifaceted within-country diversity and coexistence issues of multicultural and multiethnic counties (Plafreyman 2007: 2).

The versatile diversity issues of a within-country is often seen in terms of geo-social and politicohistorical factors. Geo-social factor refers to a situation where students attend their pre-university education within geographically demarcated homogeneous cultural context in their mother tongues. In this situation students may lack adequate cross-cultural education opportunity which would help them to cope with diversity encounters (FriesBritt, et al 2010: 183). The politico-historical factor refers to a situation in which students might be stereotypical about others that could be attributed to conflict based political and historical societal relationships. This politico-historical relation of societies of a country may manifest when students with sentiment of otherness come together for university education. This factor may instigate suspicion, mistrust and tensions among student population and may become a cause for conflict which could affect the smooth running of teaching and learning processes. In this case, diversity issues might transcend a majority-minority affair and all groups may equally miss educational opportunities that the social engagement could offer. 
Proc. of the Sixth International Conference on Advances in Social Science, Management and Human Behaviour - SMHB 2017. Copyright (๑) Institute of Research Engineers and Doctors. All rights reserved.

ISBN: 978-1-63248-141-2 doi: 10.15224/ 978-1-63248-141-2-47

Therefore, understanding the roles of socio-cultural features in an educational context might give an insight into the behavior patterns of both an individual and a group in intergroup interaction situation as well as of the nature of intergroup interaction that determine social relationships in the teaching and learning environments. That could be why Ituarte and Davies (2007: 74) argue that 'individuals' perceptions of themselves and others shape their campus experiences in ways which may influence their educational achievement." Where educational environments are welcoming, the diverse cultural perspectives and knowledge which students encounter would be an academic input and would make the learning environment enjoyable and academically productive.

\section{B. Ethnic, linguistic and religious diversity variables}

In this study context diversity variables are limited to ethnic, linguistic and religious differences and are referred to as non-disability socio-cultural differences used as identity markers and often reflect collective existence of an identity group. Based on these identity indicators, a group could be identified as an ethnic, linguistic, and/or religious entity (Taylor, Peplau and Sears 2006: 10). These diversity variables are often equivalent to race in establishing identities in educational institutions (Pattman 2007: 475).

The conceptualization of an ethnic group as a "nation" and "nationality" has been dubious because they vary in meaning from context to context. Ethnicity is often used as a sociological descriptive term to define a group as people who have common features such as language, religion, custom and history while "nation" and "nationality" often designate an ideological thought linked to the betterment of a group of people who share ideological views (Human 2005:16). Hence ethnicity is used in this study rather than "nation" and "nationality" to refer to a group of people who claim common features.

Language is not only an important medium through which information is retrieved, processed and, interpreted but is also a means through which one demonstrates membership to a group (Jarvis 2006: 58). Language plays an important role in the process of knowledge construction and is often given a central position "in the teaching and learning process" (Van Rensburg and Lamberti (2009: 69). This implies that the success of a student in learning mainly depends not only on his/her understanding of the subject matter, but also on his/her ability to reflect on the learning experiences by means of language with fellow students. In this regard, Goldstien (2003: 126) contends that "learning to negotiate across linguistic differences ... is a life skill that all students living in multilingual communities need to develop". The mutual respect and understanding that would emanate from such actions would establish sustainable inter-group cohesion which is one of the ultimate goals of education in a multicultural society. However, inter-language interaction among different language groups would depend on the role of a particular language in the inter-group communication processes. Where multilingualism is not seen as an advantage and each language group sticks to its own language domain, each group may remain aloof to the cultures and languages of counterparts. Linguistic differences could also tighten in-group connection and become a blockade to interaction with out-group students. As Schmid (2007: 166) notes, "language binds groups together and it is a powerful instrument for promoting internal cohesion and providing an ethnic or national identity".

Religion is one of the diversity factors and plays a pivotal role in social development of students. Since religion influences the spiritual growth of individuals in terms of providing meaning to life, a sense of selfcontrol over situations, and building of self-esteem, it is likely to influence the teaching learning processes (Craft, Moran, Foubert \& Lane 2011: 92-93). In addition, it is likely to have a serious impact on students' lives as it constitutes a reason for their social inclusion and exclusion (Sharabi 2011: 220). Student interreligious relationships are determined by the equal treatment of different faiths. In a religious diversity welcoming environment, religion could serve as a promoter of a social bond serving positive identity formation and become a basis for mutual trust among different religious groups. Religious based discrimination could lead students to develop a sense of otherness and might encourage them to dissociate themselves from an out-group religious social environment.

In multicultural educational contexts, ethnicity, language and religion are salient variables in the construction of identity. The current global environment by itself may dictate higher institutions to incorporate diversity issues such as ethnic, linguistic, and religious matters into education policy statements (Robinson 2009: 238). A study in Canada, for instance, showed how the increase in the social diversity in the country forced educational institutions to adopt an educational policy that explicitly address student diversity (McCown, Driscoll, Roop, Saklofske, Schwean, Kelly, \& Haines 1999: 98). The current trend shows that most countries employ multicultural approach which has been considered as a panacea to overcome diversity related student flashpoints. Nevertheless, as indicated earlier, multicultural approach is concerned with 
Proc. of the Sixth International Conference on Advances in Social Science, Management and Human Behaviour - SMHB 2017. Copyright $(\odot$ Institute of Research Engineers and Doctors. All rights reserved.

ISBN: 978-1-63248-141-2 doi: 10.15224/ 978-1-63248-141-2-47

affirmative practices of facilitating learning opportunities of non-dominant student groups within the main student population (Fries-Britt, et al 2010: 184).

In contexts where higher education programs focus on producing professional and skilled manpower for the field of work, student diversity issues might be given less attention. However, there is a need for including diversity issues into an educational policy in general and higher education in particular. It is contended that an exclusive emphasis on economic and professional skills may relegate the humane and socialization aspects of education that would contribute for the holistic development of students. Claassen (2000: 42) contends that a curriculum that aims at developing the wholesome of students should incorporate citizenship education and global knowledge and skills. He argues that both aspects should be integrated to enable students to be more efficient in both professional and social skills. The argument implies that explicitly stated diversity policy statements need to go with the socio-cultural dynamism in the society. Through this process, a policy may corroborate the progressive changes in the society.

\section{Methods}

Since this study focuses on policy analysis, it employs document analysis research design and utilizes non-numerical information to explain the study phenomenon (Corbin \& Straus 2008: 13). For the study, relevant documentary sources such as policies, legislations, diversity related reports, news papers, records, etc. were collected and analyzed thematically retrospectively to locate the position of the multicultural policy provision in addressing student socio-cultural diversity in present Ethiopian higher institutions

The study focuses on nationally and institutionally published as well as unpublished documentary resources selected on convenient basis for elucidating strategies used in addressing student ethnic, linguistic and religious differences. In the review an attempt was made to provide a wider picture of the study phenomenon.

\section{Data analysis}

The data analysis starts with a brief historical overview of strategies used to address student sociocultural differences in the Ethiopian education systems ever since the introduction of formal education and higher education. The past systems were categorized under Emperor Hailesilassie I and the Dergue eras with the assumption that the practices during the regimes would provide background scenarios for the current trends. These historical accounts were then compared with the present practices to assess progresses made in terms of promoting inter-group understanding and developing social cohesion among multicultural student population .

\section{A. The Hailesilassie I era}

The introduction of western education in general is strongly attached to Minelik II (1896-1912) for he opened the first government school in Ethiopia in the late1880s, though there had been missionary schools before that in western part of the country. Documentary sources attest that ethnic, linguistic and religious biases were decisive in that the school reflected the Coptic Christian religion as did the government of the Amhara culture and it was established to produce trained country leaders from the children of chiefs and the nobility who were mainly from the Amhara ethnic group (FMOE 2002: 1; Krylow 1994: 23). It could be inferred that students were homogeneous in ethnic, linguistic and religious terms since they were recruited from Amhara royal group.

Significant progressive changes were attained in expanding education during Emperor Hailesilassie I, from late 1920s up to1974. Schools started to accommodate students of heterogeneous backgrounds, but the non-Amahara children were expected to be assimilated into the Amhara culture. Krylow (1994: 232) witnesses that "in the early times the success of non-Amhara [depended] on accepting [the] 'Amharanised' way of life". Krylow (1994) (in references here) also refers to this process as 'Ethiopianisation' which essentially meant 'Amaranisation'. The concept 'Amharanisation' emerged after the Amhara ethnic group which had been politically dominant ever since the formation of the present Ethiopia in the late $19^{\text {th }}$ century. With regard to language, Amharic had constitutionally enjoyed the privilege as national language and had been taught as the language of unification since 1880 s.

During the Hailesilassie I era some colleges and a university was established. These institutions were governed by policy objective which dictated that Ethiopian students had to be Ethiopianised in character and Christianized in religion (Abebe \& Pausewang 1994: 35; Krylow 1994: 231). Thus, during the regime, "all talented students... had equal opportunities" for education at all levels as far as they accepted the religious (Coptic Christian) and linguistic (Amharic) behavior expected of them (De Stefano \& Wilder 1992: 10). It should be noted that at that time it was mandatory for students to score a pass mark in Amharic in order to join a university. 
Proc. of the Sixth International Conference on Advances in Social Science, Management and Human Behaviour - SMHB 2017. Copyright (๑) Institute of Research Engineers and Doctors. All rights reserved.

ISBN: 978-1-63248-141-2 doi: 10.15224/ 978-1-63248-141-2-47

In general, the main aim of education during Minelik II and Emperor Hailesilassie I periods was to Ethiopianise the content of education so as to convert the non-Christian children to Coptic Christian and to promote the 'national language', Amharic.

\section{B. The DergUE era}

The whole educational processes during the Hailesilassie I era were truncated by the 1974 revolution which brought the Dergue regime to power. The word Dergue is an Amharic concept used to refer to the Coordinating Committee of the Armed Forces (Military government) which ruled the country from 1974 up to 1991. The regime declared that it abolished the feudal assimilationist education system that had burgeoned social, cultural and religious inequality in the country. It claimed that it revamped an education system that brought about equitable education to all people. It also proclaimed that "the Ethiopian Democratic Republic ascertains the equality, development and respect of the languages of the nations and nationalities" (EDR 1988: 18). Indeed it had made a significant reform to the education system compared to the monolithic religious and linguistic based assimilationst educational policies of its predecessor. The number of schools and students had shown a significant increase (De Stefano \& Wilder 1992: 15-16) that it could be assumed that compared to the Imperial era, different ethnic groups in the country had got more access to education. This would mean that the educational opportunity paved the way for students from different socio-cultural backgrounds to come together for higher education. It also succeeded in secularizing the education system as opposed to the modus operandi of the earlier regime.

With regard to higher education institutions, the Dergue regime installed socialist education policy through the Higher Education Institutions Administration Proclamation No109/1977 (EPMG 1977) which was meant to enforce the higher education in the fight against capitalism and for the development of socialism. However, the regime was criticized for a number of setbacks in its strategies of addressing student differences. Although it claimed it had brought a revolutionary change in education system, its policy remained similar to that of the Hailesilassie regime (TGE 1994: 2). Some diversity issues were addressed by following the footsteps of the earlier government. For instance, even though Amharic was relegated from national language to the level of office language, it remained the medium of instruction up to junior secondary school and the means to success for getting employment opportunities in the country (Saint 2004: 84).

\section{The EPRDF government multicultural approach}

The EPRDF government has explicitly set constitutional and policy frameworks which it believes responds to the long standing diversity issues in Ethiopia. One of the policy responses was the endorsement of the Ethiopian Education and Training Policy (1994) which stipulated a multicultural policy for treating student differences.

The socio-cultural differences in the country have been given legitimacy. The constitutional rights to be different anchor the policy that regulates the functions of all sectors, including the education sector. This implies that socio-cultural diversity issues have been positioned within a multicultural paradigm. The explicit statement of the multicultural constitutional provision with regard to socio-cultural diversity of the peoples could be considered as a significant development compared to the previous regimes which emphasized on assimilation and integration. In order to address ethnic, linguistic and religious identity issues), it has established ethnic based regional states (De Stefano \& Wilder 1992: 15). This was an underlying difference between the past regimes and the EPRDF government.

\section{The Ethiopian Education and Training Policy (1994) and the Higher Education Proclamation no, 650/2009}

The constitutional provisions and premises informed the formulation and implementation of the Ethiopian Education and Training Policy (1994). Concerning language, it stipulates the use of mother tongue as the medium of instruction for primary education. As a result now more than 24 languages are used as medium of instruction for primary and junior secondary education and some languages are taught as subjects in high schools and higher educational institutions. For instance, during the data collection, Afan Oromo and Tegregna have been incorporated into higher education curriculum as study disciplines.

The implementation of the Ethiopian Education and Training Policy in higher education was supplemented by the Higher Education Proclamation no 351/2003 (FDRE 2003) and Higher Education Proclamation no, 650/2009 (FDRE 2009). According to the proclamations, the entry assessment score for students from the "emerging regions" should be lower than that for students from the relatively affluent regions. The "emerging regions" are assumed to have little access to education compared to the relatively affluent regional states. Since the provisions of equitable access and institutional services are provided on identity bases, it could be assumed that the education system emphasizes affirmative strategy of multicultural approach. 
Proc. of the Sixth International Conference on Advances in Social Science, Management and Human Behaviour - SMHB 2017. Copyright $(\odot$ Institute of Research Engineers and Doctors. All rights reserved.

ISBN: 978-1-63248-141-2 doi: 10.15224/ 978-1-63248-141-2-47

The above affirmative provision is meant to increase student composition at various higher institutions and that the government has planned to continue to provide allowances for those which it considers as disadvantaged social groups. This approach seemed to be inherently consistent with the multicultural policy premises. It is affirmative in that the provision targets the disadvantaged groups.

\section{E. Diversity climate of Ethiopian higher education institutions}

Different documentary sources indicate that since the implementation of the multicultural policy, intergroup conflicts that involve individuals or groups from different social groups have happened at different institutions at different times. This could be explained by two similar episodes. One of these was an ethnic based conflict surfaced at the Adama Science and Technology University when a student from Oromo and the other from Tigrean backgrounds, disagreed on the choice of TV channel in December 2011 (Addis Guday 2012: 10). It was reported that the disagreement between the two individuals immediately took the shape of ethnic conflict and resulted in death of a student, injuries of 11 students, imprisonment and dismissal of some students. The second was an episode at Bahir Dar University, a conflict between a student from Tigray and a campus police who was presumably from Amhara ethnic background was transformed into ethnic conflict between the Amhara and Tigray students (Addis Guday 2011: 1).

The ethnic conflicts are sometimes coupled with language based hostilities. Intergroup conflict erupted when some students from the Amhara ethnic group showed stereotypical attitudes and attempted to forbid the Oromo student group not to use the Oromo language in the dorm because they were suspicious about the intent of the language users (Addis Neger (2008: 22). This was viewed as a reflection of stereotype attitude by the counterpart group and led to a violent interethnic conflict.

Although documentary data show that religious hostilities are not as frequent as ethnic and linguistic hostilities, there have been noticeable religious based student mistrusts and suspicions at some Ethiopian universities. The conflicts were manifested in different forms. Firstly, some of such incidents surfaced when a certain religious group was of the opinion that another religious group enjoyed special privileges from the government or the university administration. In 2012, for example, the Muslim students at Debreberhan University complained that the University outlawed wearing clothes displaying religious identity on campus, whilst their Orthodox Christian counterparts were allowed to wear the Netela (a cotton wrap cloth) on campus while on their way to and from church services (Addis Guday 2012: 10). The alleged preferential treatment resulted in mistrust between the complaining student group and the University administration as well as between the two religious groups.

\section{Discussion}

The treatment of socio-cultural differences amongst students by different Ethiopian governments ranged from an assimilationst and integrationist positions of the Hailessilassie I and the Dergue regimes respectively to the multicultural approach of the present EPRDF government The study shows that the perspectives of Ethiopian governments for addressing student socio-cultural differences has developed from a total neglect of student differences to an extra emphasis on some of diversity issues of the present EPRDF government. For instance, social differences related to ethnic, linguistic, and religious differences had not been recognized during the Hailesilassie I; whereas these issues were highly emphasized by the EPRDF government since 1994. In spite of the multicultural affirmative practices by the EPRDF government, student intergroup, mistrust and hostility have prevailed since the multicultural policy implementation.

The analysis also shows that stereotypical attitudes and prejudices shown to others by a majority identity group could not be tolerated; it rather develops into intergroup hostility. This situation confirms that the multicultural policy paradigm which has been used to manage majority-minority relations might not resolve mistrust, suspicion and hostility among competing within-country identity groups

\section{Conclusion}

This research shows that equality of opportunity is not congruent with adequate education as the holistic development in a multicultural country needs students' cross-cultural knowledge and development for a multicultural work environments and collective citizenship. Since the students are citizens and live together in the country, the multicultural policy provision and the increase in student composition would presuppose the need for a more accommodative approach that would avoid antagonistic relations amongst students and promote mutual understanding between the disadvantaged and the advantaged groups. In short, the inter-group social development strategies of the education system need to be transformed from the affirmative based multicultural approach of "unity within diversity" to transformative diversity management approach in which students learn not only "I am, because you are" but also the equal celebration of diversity: "I am, because we are". 
Proc. of the Sixth International Conference on Advances in Social Science, Management and Human Behaviour - SMHB 2017. Copyright $(\odot$ Institute of Research Engineers and Doctors. All rights reserved.

ISBN: 978-1-63248-141-2 doi: 10.15224/ 978-1-63248-141-2-47

\section{Recommendation}

The study requires a wider investigation at national and institutional levels to come up with working recommendations. However, the following tentative recommendations are forwarded as alternative approaches to manage the student diversity at Ethiopian higher education institutions.

1. Universities should institutionalise diversity management strategies in which students experience the socio-cultural diversity of the country.

2. The present multicultural policy should be reviewed from a diversity management perspective to guide institutional diversity management in terms of planning, implementation and evaluation practices.

3. The universities should formally set in place intercultural competence development programmes for students.

4. Diversity planning and implementation in terms of staffing and services should serve as a tool for measuring quality at the universities.

\section{References}

Abdi, A. .A \& Cleghorn, A. 2005. Sociology of education: theoretical and conceptual perspectives, in A.A. Abdi \& A. Cleghorn. (eds.). Issues in African education: sociological perspectives. Palgrave: Macmillan, pp 3-24.

Abebe Zegeye. \& Pausewang, S. 1994. Ethnic factors in post-Mengistu Ethiopia, in Abebe Zegeye \& S. Pausewang. (eds.). Ethiopia in change: peasantry, nationalism, and democracy. London: British Academic Press, pp 231-241.

Balsvik,R.R. 2007. The quest for expression: state and the university in Ethiopia. Addis Ababa: Addis Ababa University Press.

Claassen, C .2000. The state, globalisation and education in E. Lemmer (ed.). Contemporary education: global issues and trends. Sandton: Heinemann Higher and Further Education (ply) Ltd. P: 26-45.

Corbin, J \& Straus, A. 2008. Basics of qualitative research: techniques and procedures for developing grounded theory. London: Sage Publications Ltd.

Craft, C. Moran, Foubert, J. D. \& Lane, J. J.2011. Integrating religious and professional identities: Christian faculty at public institutions of higher education. Religion \& Education, 38 (2): 92-110..

Dancy II T.E. 2010. When and where interests collide: policy, research, and for managing campus diversity, in T.E Dancy II .(ed).
Diversity management (re)visioning equity on college campuses. New York: Peter Lang pp: 71-95.

De Stefano, J. \& Wilder, B. 1992. Ethiopia Education Sector Review USAID Preliminary Report. (n. p.).

Ethiopian Democratic Republic (EDR). 1988. Ethiopian democratic republic (EDR) constitution No.1/1988 Negaret Gazetta. Addis Ababa.

Figueroa, P. 1999. Multiculturalism and anti-racism in a new era: a critical review. Race, Ethnicity and Education, 2 (2): 281-302.

Federal Ministry of Education (FMOE). 2011. Social assessment for education sector in Ethiopia. Addis Ababa: Ministry of Education.

Federal Ministry of Education (FMOE) 2005. Education sector development programme III (ESDP-III) 2005/2006 2010/2011 (1998 efy 2002 efy) programme action plan. Addis Ababa: Ministry of Education 2002.The Educational and training policy and its implementation. Addis Ababa: Ministry of Education.

Fries-Britt, Y., Younger, T. \& Hall, W. 2010. Underrepresented minorities in physics: how perceptions of race and campus climate affect student outcomes, in T.E. Dancy II (ed.). Diversity management (re)visioning equity on college campuses. New York: Peter Lang pp: 181-198.

Gillborn, D. 1990. 'Race', Ethnicity and education: teaching and learning in multiethnic schools. Routledge

Glazer, N. 1997. We are all multiculturalists. New Cambridge: Harvard University Press.

Goldstein, $\mathrm{T}$.2003. Teaching and learning in amultilingual school: choices, risks, and dilemmas. Mahwah: Lawrence Erlbaum Associates, Publishers.

Higher Education Institutions Administration Proclamation No109/1977 (EPMG 1977).

Higher Education Proclamation no 351/2003 (FDRE 2003).

Higher Education Proclamation no, 650/2009 (FDRE 2009

Human, L 2005. Diversity management for business success. Van Schaick Publisher.

Jarvis, P. 2006. Towards a Comprehensive Theory of Human Learning: Lifelong Learning and theLearning Society, Volume I. London:Routledge.

Krylow, A. 1994. Ethnic factors in post-Mengistu Ethiopia, in Abebe Zegeye \& S. Pausewang (eds.), Ethiopia in change: peasantry, nationalism and democracy. London: British Academic Press.

McCown, R.R.; et al. 1999. Educational psychology: a learning centre approach to classroom 
Proc. of the Sixth International Conference on Advances in Social Science, Management and Human Behaviour - SMHB 2017. Copyright $\odot$ Institute of Research Engineers and Doctors. All rights reserved.

ISBN: 978-1-63248-141-2 doi: 10.15224/ 978-1-63248-141-2-47

practice (( $2^{\text {nd }}$ ed.) Scarborough: Allyn \&Bacon.

Ministry of Finance and Economic Development (MOFED). 2010. Growth and transformation plan 201/11-2014/14 (Vol.1) Addis Ababa: MOFED.

Onsman, A. 2010. Cross-border teaching and the globalisation of higher education: problems of funding, curriculum quality, and international accreditation. Lewiston: The Edwin Mellen Press.

Palfreyman, D. 2007 Introduction: learning and teaching across cultures in higher education in D. Palfreyman. \& D. L. McBride (eds.). Learning and teaching across cultures in higher education. Palgrave, pp 1-10.

Pattman, R. 2007.Student identities and researching these, in a newly 'racially' merged university in South Africa. Race, Ethnicity and Education, 10 (4): 473-492.

Robinson, Viviane M.J. 2009. Why do some policies not work in schools?, in H. Daniels, H. Lauder \& J. Porter (eds.). Knowledge, values and educational policy: A critical perspective. London: Routledge, pp 237-252.

Saint, W. 2004. Higher education in Ethiopia: the vision and its challenges JHEA/RESA. 2(3): 83-114.

Schmid, C.L. 2001.The politics of language: conflict, identity, and cultural pluralism. Oxford: Oxford University Press.

Sharabi, M. 2011. Culture, religion, ethnicity and the meaning of work: Jews and Muslims in the Israeli context in Culture and Religion, 12 (3): 219-235.

Shizah, E. \& Abdi, A. A. 2005. Democratizing education in Zambia: socio-historical analysis, in A. A. Abdi \& A. Cleghorn (eds.). Issues in African education: sociological perspectives. Pagrave Macmillan, pp 241-258.

Taylor, S.E, Peplau, L. A. and Sears, D. O. 2006. Social psychology $\left(12^{\text {th }}\right.$ ed.) New Jersey: Pearson Prentice Hall.

TGE .1994. Education and Training Policy. April. E.E.P-86

Tjeldvoll, A. Welle-Strand, A. \& Bento, F. 2004.The complex relations between university, society and state: the Ethiopian predicament in establishing a service university. JHEA/RESA 3 (1): 51-75.

References in the medium of local languages

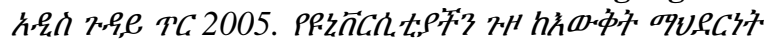

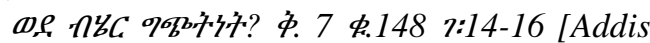
Guday 2013 The Journey of our University from source of knowledge to ethnic conflicts vol. 7 no 148 pp: $14-16$.

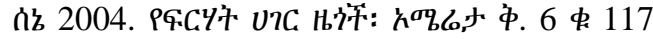
7:10-13 [Addis Guday. June 2012. Citizens of a country with fear vol. 6 no. 117 pp:1013]

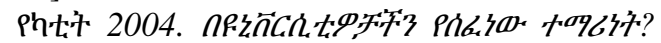

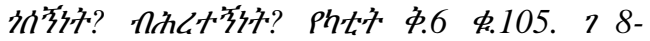
10 [Addis Guday 2012 ['what has Reigned in Our Universities studentship? clanship? Ethnicity? Feb. vol.6 no, 105 pp: 8-10]

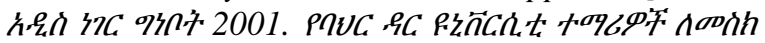

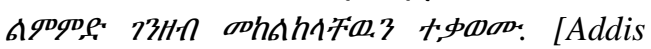
Neger May 2009 Bahir Dar University Students protested against the denial of field trip allowance no, 085. 